\title{
5 MAPPING SOCIAL NETWORKS IN SOFTWARE PROCESS IMPROVEMENT: An Action Research Study
}

\author{
Peter Axel Nielsen \\ Gitte Tjørnehøj \\ Aalborg University \\ Aalborg, Denmark
}

\begin{abstract}
Software process improvement in small, agile organizations is often problematic. Model-based approaches seem to overlook problems. We have been seeking an alternative approach to overcome this through action research. Here we report on a piece of action research from which we developed an approach to map social networks and suggest how it can be used in software process improvement. We applied the mapping approach in a small software company to support the realization of new ways of improving software processes. The mapping approach was found useful in improving social networks, and thus furthers software process improvement.
\end{abstract}

Keywords Software process improvement, agile software development, social network analysis, action research, collaborative practice research

\section{INTRODUCTION}

Software process improvement (SPI) has long been a concern for software producing companies and researchers. The development of the capability maturity model (CMM) by the Software Engineering Institute sparked a huge interest in the field. The first reports on CMM and similar models were promising; however, in later years an increasing number of failures have been reported by Hansen et al (2004). According to Hansen et al, very little research on SPI is reflective and critical. The CMM can be taken to be a prototypical example of the formal and model-based approaches. CMM requires many improvements and also improvements of significant complexity (Aaen et al. 2001), and according to Ngwenyama and Nielsen (2003) SW-CMM in particular is based on a rational ideal and the idea of the rational culture for software development. 
A small software company, called AlphaSoft here for anonymity, where we conducted the action research, is an organization with fewer than 50 software developers. Along with the company, we have a knowledge interest in software development and SPI in small software companies. Other SPI researchers have a similar interest. Within the SPI community, there has long been the concern that the better known approaches, such as CMM, are not adequate for the improvement issues in small software companies. An early survey shows major concerns that the CMM does not fit small software companies (Brodman and Johnson 1994). There is some agreement on the particular problems facing small companies pursuing SPI: low likelihood of investment in improvement, poor fit with small-company culture, lack of SPI knowledge, lack of action planning, and more sensitivity to changing environments (CaterSteel 2001; Kelly and Culleton 1999; Villalon et al. 2002; Ward et al. 2001).

Recently, there have been several attempts to develop and test new SPI approaches for small software companies. Some software companies choose to improve software processes in a less formal and less model-driven way. For example, in Kelly and Culleton's (1999) research, company S3 chose an approach informed by the CMM, but based on alternative principles: (1) maximize involvement, minimize disruption; (2) stress quality, not CMM compliance; (3) emphasize the advisory role; and (4) promote efficiency. Reporting on similar efforts, Iversen et al. (1999) and Nielsen et al. (2002) primarily focus on alleviating problems experienced rather than finding discrepancies between software practices and process-maturity models. Villalon et al. (2002) suggest an action package concept to overcome lack of follow-through into action planning and action plan implementation, particularly in small software companies. Richardson (2002) suggests utilizing quality function deployment and has developed a device called the software process matrix to determine the relationships between processes and practices.

Small software companies often face changing environments and, therefore, can easily be more vulnerable than large companies. Ward et al. (2001), addressing software development in small companies, suggest that "the processes by which software is developed are likely to change with circumstances-perhaps even change dramatically-even while general principles like the need for good communication remain constant" (p. 105). Within SPI, Börjesson and Mathiassen (2004) have addressed this desired agility and conclude that, for software development, the agility challenge comprises the need to

- Handle changes in customers' requirements

- Be aware of and respond to technological changes and innovations as well as changes in the market

- Implement software process improvement

Most small software companies focus on the first two challenges. Börjesson and Mathiassen, furthermore, state that an agile software organization needs to balance and coordinate development, improvement and innovation. However, all of these studies on SPI in small software companies found that that is exactly what these companies are not doing. They prioritize development over improvement.

Through action research, we are collaborating with a small software company. For almost a year, we joined efforts in trying to follow the rational ideal informed by model- 
based assessments. Several improvement initiatives suffered premature death and the effort was eventually brought to a halt. Recently, we have tried to recover the SPI process by following an alternative route in which we map social networks, among others. Our initial interest in social networks came partly from the practical desire to understand whether AlphaSoft had an appropriate foundation for a less managementdriven SPI approach, and partly from the knowledge that organizational influence processes are hugely important in SPI (Nielsen and Ngwenyama 2002).

Social network analysis is presented in section 2. In section 3, we outline our research approach and in particular we focus on the research process. That leads us to section 4, where we present how we mapped social networks in AlphaSoft and the experience gained from this. In section 5, we discuss the usefulness of the mapping approach in SPI and the implications for SPI and research. The paper ends with section 6, where we draw our conclusions. Altogether, in this paper we address the research question: To what extent and in which ways is the mapping of social networks useful in SPI in a small company?

\section{SOCIAL NETWORK ANALYSIS}

Social network analysis is a framework and a set of techniques applied to study the relationships between organizational actors and their exchange of resources. Organizations are viewed as consisting of actors linked together in networks through action, exchange, and interpretation and sharing of resources such as information and knowledge. Actors are viewed as interdependent. There are relational ties between actors through which resources are exchanged. Network models conceptualize structure as lasting patterns of relational ties (Wasserman and Faust 1994). Wasserman and Faust further define actors as discrete individual, corporate, or collective social units (i.e., not only as a single person). The relational ties can be of varying types: evaluation of one person by another (as with friendship), transfer of material resources, affiliation, authority (as between managers and subordinates), and behavioral interaction, like sending messages and engaging in a discussion (Wasserman and Faust 1994, p. 18).

Social network analysis is not a new approach. It has been developed and applied in a large number of organizational studies. (For historical accounts, see Scott 2000; Tichy et al. 1979; Wasserman and Faust 1994.) The framework does not give the unit of analysis and data may be collected about many different kinds of actors and relational ties. It is, however, common to collect data about the contents of the relational ties as well as their intensity and reciprocity. Having collected the data, the approach requires the study of network properties and structural characteristics are considered crucial. The structural characteristics are, for example, network size, density, clustering, reachability, centrality, star, liaison, bridge and gatekeeper. Tichy et al. (1979) define these as

- Density: the number of actual relational ties in the network as a ratio of the number of possible relational ties

- Centrality: the degree to which relations are guided by the formal organization

- Star: the individual with the highest number of relational ties (also called the central actor) 
These are just a few of the analyses that can be performed on the total network. The analyses all have a foundation is graph theory (Borgatti and Everett 1992; Scott 2000; Wasserman and Faust 1994), but the interpretation and the semantic implication of these analyses remain specific to the setting where the data were collected.

Social network analysis has been applied in information systems research. Zack (2000) argues that social network analysis can be used to explore the impact of information systems on organizational forms. Temdee and Korba (2001) apply social network analysis to measure the appropriateness of computer-based systems supporting cooperative work. In studies of computer-supported collaborative learning, social network analysis has been applied to logs of interaction between learners (Martínez et al. 2003). Social network analysis has also been used in the study of exchange of information (Haythornthwaite 1996)

Our application of social network analysis focuses on the social networks through which software process improvement may happen. We have chosen to apply interactional analysis. Tichy et al. claim that it is easy to gather data for interactional analysis and that it has all the benefits of the other analyses (positional, reputational, and decisional). They describe interactional analysis as an approach that focuses on interactions, influence, feedback and power.

\section{ACTION RESEARCH APPROACH}

The research is part of a national research project on software process improvement and knowledge management. The project involves three software companies and researchers from three research institutions. The research approach has been action research of the type that is called collaborative practice research (Iversen et al. 2004; Mathiassen 2002). Collaborative practice research is action research supplemented with field experiments and practice studies.

A software process improvement project was created in AlphaSoft as an action research project. Serving a dual purpose is a core characteristic of action research (Hult and Lennung 1980; McKay and Marshall 2001). In this case, the researchers' intervention in AlphaSoft served the dual purpose of collaborative problem solving focused on software processes and contributing to SPI research. Action research was chosen because it was the intention to create immediate linkage between theories and practice for the benefit of practical problem solving and for the benefit of testing and building practice-based theories. Action research at its best does exactly that: it validates findings through immediate action.

The research reported in this paper is a small part of the whole collaborative practice research effort. The action research process follows the process outlined by Iversen et al. (2004) and McKay and Marshall (2001).

The action research process is specifically directed at assessing the usefulness of mapping social networks in SPI in a small software company. We did not design this process before, or even at the beginning of, our intervention. The process came about after several unsuccessful attempts at facilitating improvement of the software processes in AlphaSoft. The appreciation of the problem situation led to a study of the relevant literature (see section 1). We realized only gradually that social network analysis might 


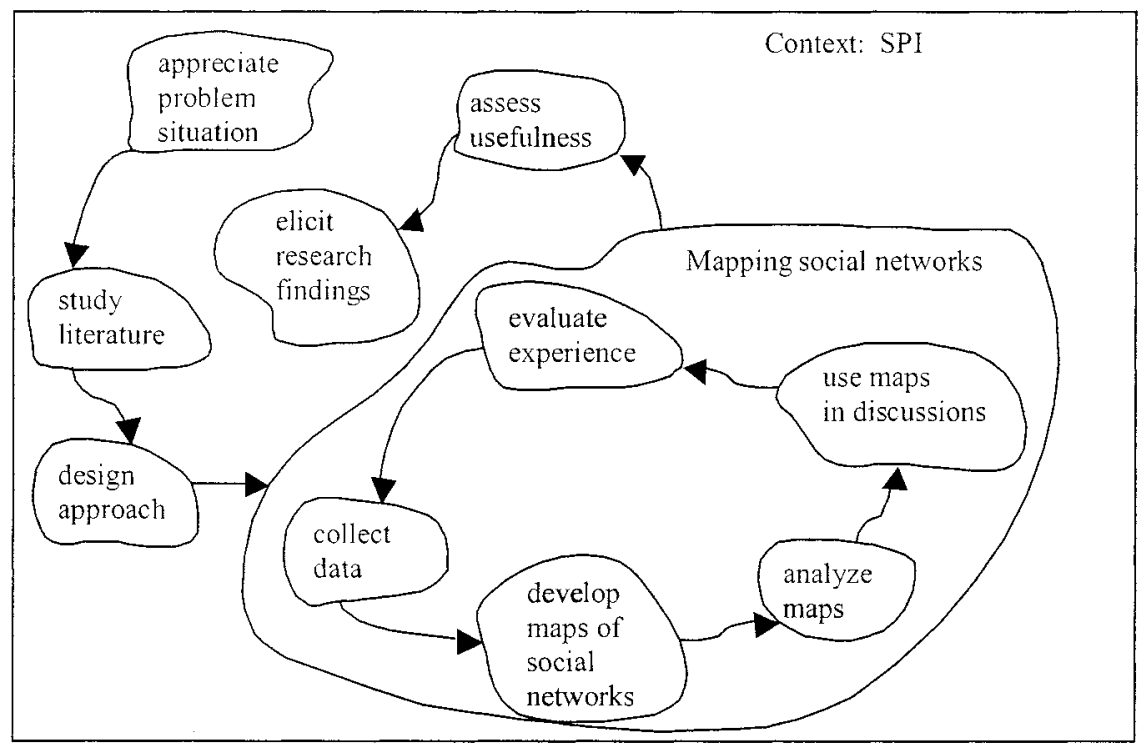

Figure 1. The Action Research Process (based on Iversen et al. (2004) and McKay and Marshall (2001))

offer insights that our clients, and we, needed. That led us to study the literature on social network analysis (see section 2). Based on this, we designed an approach through which we could collect the necessary data, develop the maps of social networks, analyze the maps, use the maps in discussions and evaluate the resulting experience (see Figure 1). In the following sections, we present the applied approach: a description of the situation that we entered (section 4.1); the data collection (section 4.2); the different maps and how they were developed (sections 4.3,4.4, and 4.5); the action researchers' analysis of the maps (section 4.6); and the use of the maps in a discussion with an SPI manager and the joint evaluation of the experience (section 4.7).

The action research and the mapping approach was later assessed in terms of the six criteria form Iversen et al.: roles, documentation, control, usefulness, theory, and transfer (see section 5).

\section{MAPPING SOCIAL NETWORKS IN SPI}

The mapping of social networks followed the approach in Figure 1.

\subsection{The Situation Appreciated}

AlphaSoft is a small software company with two departments. The ERP department develops a large ERP system and maintains it at a number of customer sites. The tasks 
are characterized by long-term and close contacts with few customers. The software developers have much domain knowledge within logistics in the particular area where their customers operate. The head of this department is also responsible for the quality system and the ISO9000 certificate. He was a key actor in the SPI group, where the head of the tailor-made department was also a member. The tailor-made department develops several tailored systems for many different customers. Their products range from traditional administrative systems to Web portals. The application domains vary and the developers' primary expertise lies within software engineering and project management.

Previously, improvements in software development were informal and spread through collaboration and informal contacts with colleagues. A few significant improvements attracted management's attention and were taken to be company improvements. One such improvement even turned into an internal software development project. Most improvements, however, remained personal or local between a few colleagues.

When the action research began, the company was introduced to basic SPI approaches and soon top management announced the slogan "CMM level three-in three years." This is a quite common slogan for newcomers to SPI. An SPI group was formed and a developer from each of the departments was appointed to the group. The group took on the responsibility of assessing the current practices, planning improvement initiatives, and implementing these. Successful improvements were also supposed to be added to the existing quality system. The manager of the ERP department later characterized the whole set-up as a complete failure. His perception is that some developers felt pushed aside and that others stopped focusing on improvements, waiting for the results from the SPI group. The group lacked time and resources and organized only one improvement initiative. Add to this market decline and consequently low sales figures, which led the company to shift its focus toward sales work and the monthly sales figures.

Despite these setbacks, AlphaSoft's management recognized the value of their previous improvements as vital for their business success and found it necessary to proceed. The two department managers' perception was that future improvements must be rooted in a strategy that provides faster feedback as well as visible and immediate benefits for software developers. It was in this atmosphere that the mapping of social networks was initiated.

\subsection{Social Network Analysis of SPI}

For the purpose of mapping social networks, we collected the data following the principles of the interactional methods in social network analysis (see section 2). The data consist of developers' and managers' individual perceptions of their communication on issues of improvement in the company during the last six months in retrospect. They were asked to identify and characterize the communication as they remembered it. For each interaction, they were asked to assess whether the communication had been

- Formal or informal

- Written or oral

- Downward, upward, or lateral 


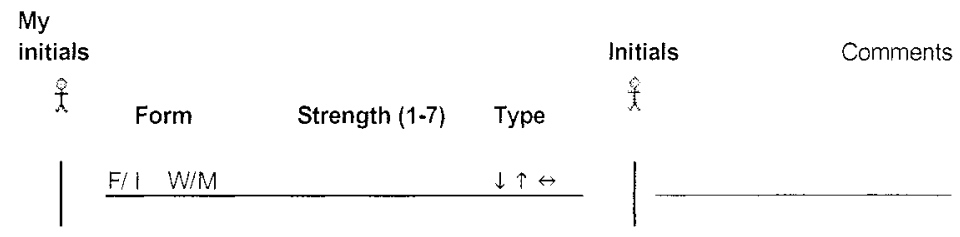

Figure 2. Graphical Questionnaire (Extract)

The first two we refer to as the form of communication. The last refers to the direction of the organizational influence as described by Kotter (1983). The developers and managers were also asked to assess the weight of the communication on a scale from 1 to 7 where 1 is very low (e.g., receiving an e-mail) and 7 is very high (e.g., collaboration or continuous dialogue). We developed a graphical questionnaire as an aid to be filled in by the developers and the managers (see the extract, Figure 2).

We loaded the data into NetDraw. NetDraw is a tool for social network analysis that can display graphs with actors as nodes and relationships as edges. Both nodes and edges can have attributes. The data is stored as an Ucinet dataset and can be loaded directly into the tool.

The tool offers various display features and analyses automatically performed by graph algorithms. We used the tool to analyze and keep an overview of the data (e.g., to select parts of the graph, show different attributes and weights, identify central actor, cut-point, etc.) using graphical elements to visualize structures in the social networks. We performed a systematic analysis of the data to elucidate the following network structures:

- Centrality, peaks, and blocks

- Components, k-cores, and cut-points

- Ego-networks, distribution of strengths, form, and influence in the social networks

In the presentation of the maps that follows we focus on the most important structural features disregarding maps that were neither important nor relevant in understanding the specific SPI effort in AlphaSoft.

\subsection{The Basic Map}

We chose a basic map as a starting point and maintained the same layout in all maps in order to increase visual comparability.

The basic map of social networks is shown in Figure 3. Diamonds are actors in the ERP department; circles are actors in the tailor-made department; actors are numbered for anonymity; managers are prefixed with an M; M-9 is the CEO. The basic map shows only one component, as a path exists between all actors with at least one tie. The ties between the two departments are few, but within the departments the networks are dense and almost evenly distributed. M-19 is the central actor as he is the actor with the highest degree, i.e., the numbers of ties: (11). M-19 is also a peak as he is more central 


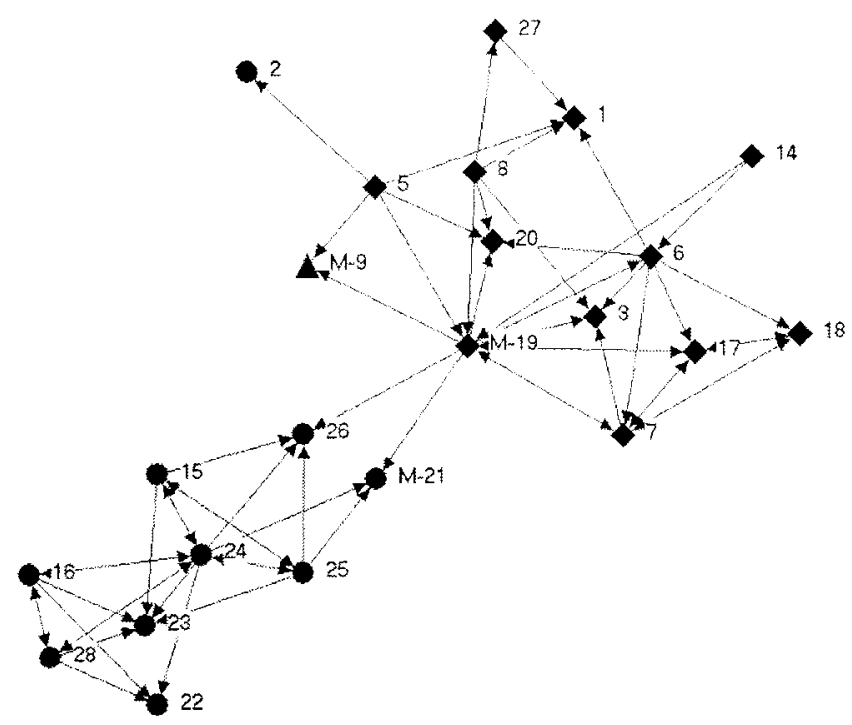

Figure 3. Basic Map of Social Network of SPI Activity

than any other actor to which he is connected. Developer \#6, although highly connected with a degree of 8 , is not a peak as he is connected directly to M-19. This is not surprising as M-19 is the manager of the ERP department and responsible for the quality system, the ISO 9000 certificate, and a key actor in the SPI group. He is connected to the top manager, M-9, and all connections between the ERP department and tailor-made goes through him.

M-21, the manager of the tailor-made department, is far from central and not a peak. He shares the contact with the ERP department with developer \#26. In the tailor-made department, developer $\# 24$, with a degree of 8 , is the only peak and he is connected to all in the department. The path from any of the managers to any of their developers is less than or equal to 2 edges. In the ERP department, this is due to the central role of the manager, and in the tailor-made department, to developer \#24.

\subsection{The Maps of $3 k$-Cores, Cut-Points and Components}

Figure 4 shows three maps that contribute to the understanding of the overall social networks. The $3 k$-core displays the actors with a degree greater than or equal to 3 . This map is not significantly different from the basic map as only three developers in the ERP department are cut out. The $3 k$-core map shows the connectivity of the network and that the inner coherence of the company seems relatively strong. Actors M-19 and \#5 are cut-points because if just one is removed from the network it will break into two components. Developer \#5 is a marginal cut-point as he will only cut out one other actor. M19 , on the other hand, is important because he is the cut-point between the ERP depart- 


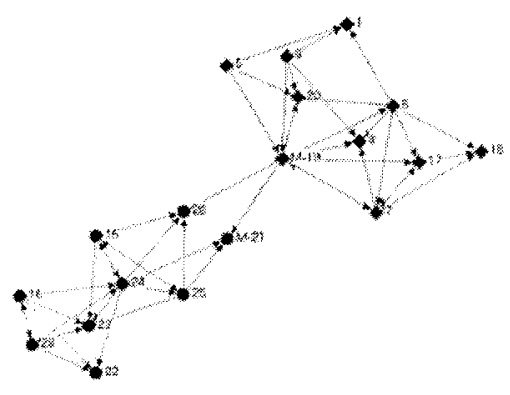

$3 k$-Cores

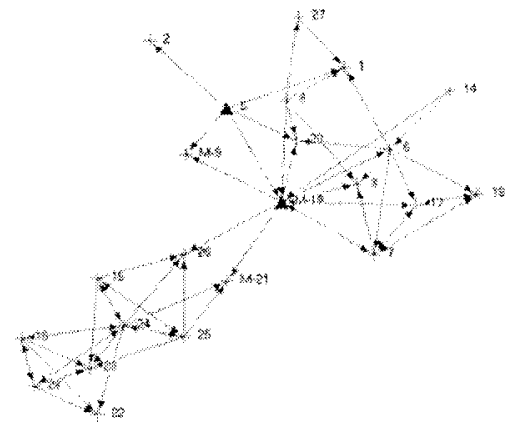

Cut-Points

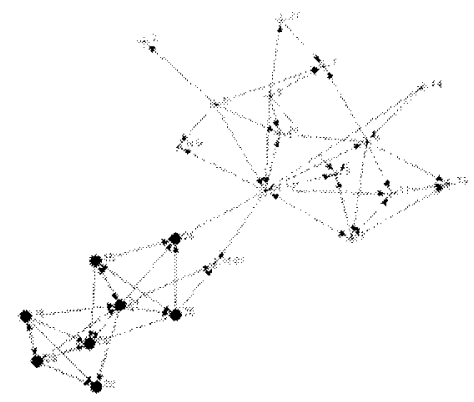

Components

Figure 4. Three Different Maps Based on Graph Analysis

ment and the tailor-made department. The components map shows a similar tendency for the network to break into two since the two identified components coincide with the departments. The only exception to this is that manager M-21 of the tailor-made department, from a graph theoretical viewpoint, has a stronger tie to the ERP department than to his own department.

\subsection{The Maps of Attributes}

Figure 5 shows the attributes of communication. Communication is mostly informal and all actors are involved in informal communication. Formal communication is only found around the two peaks and between the two departments. Written communication department has a stronger presence in the tailor-made department and around the manager of the ERP department. Oral communication is widespread and every actor participates in oral communication. It is worth noticing that communication between the departments is formal but oral. 


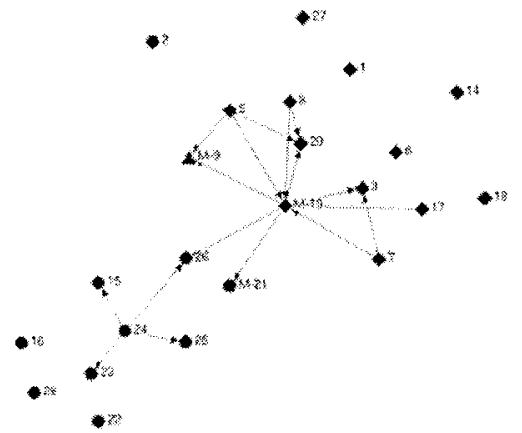

Formal

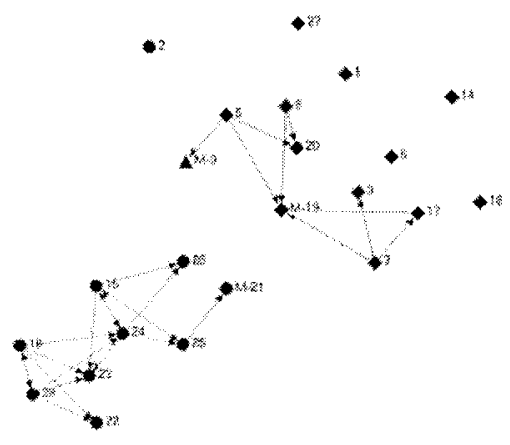

Written

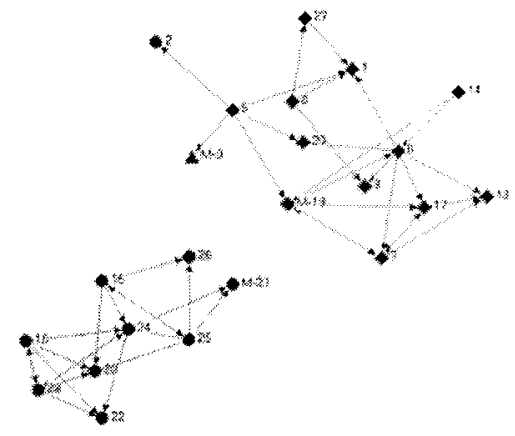

Informal

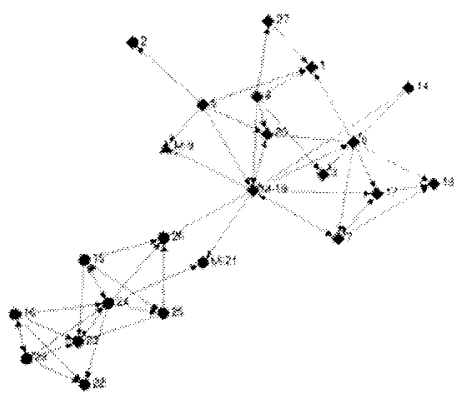

Oral

Figure 5. The Maps of Attributes in the Social Networks

Figure 6 shows two maps resulting from analysis of weights. The highest weights map shows the highest weight reported for all ties. Overall, the high weights seem evenly distributed over the departments, but weights are rather low between the departments. The only communication of weight 7 is between the manager of the ERP department and developer \#6 (who is very well connected in that department). The rest of the ties involving M-19 are somewhat weaker. If developer $\# 6$ and M-19 are both removed from the map, the department falls apart; they are the backbone of the department.

\subsection{The Researchers' Analysis}

We, the action researchers, produced the following analysis of all of the maps. This analysis was presented to the SPI manager during the next step in the approach.

The overall picture of social networks shows two departments with an informal, mostly oral and widespread interaction within the departments, but with sparse contact 


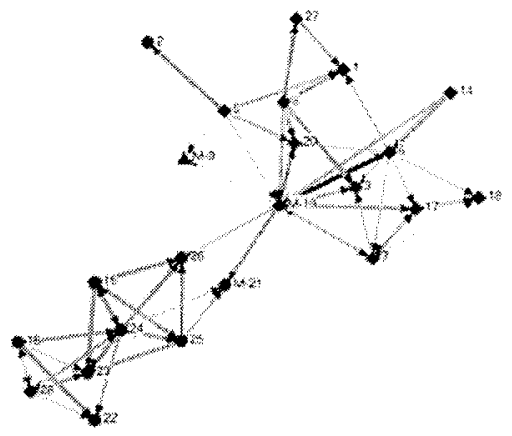

Highest Weights

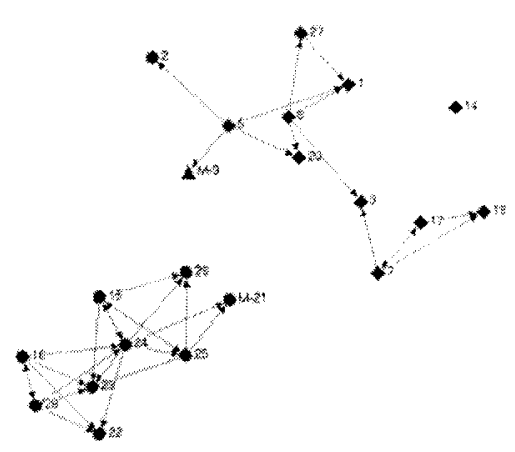

Map Without M-19 and Actor 6

Figure 6. Two Maps Based on Analysis of Weights

between departments and to top management. The ERP department has a central manager, M-19, "gatekeeping" the department against all the other actors in the company in a more formalistic way than usual in the company. He controls the communication on improvements both within his own department and also at the management level and he is the only middle manager with contact to the top management.

The tailor-made department seems to have an internal central player in developer \#24 keeping the department together and communicating intensively with many. The manager of the department, M-21, only plays a small role in SPI as he has few ties and partakes in lightweight communication. He only connects to the whole department through developers \#24 and \#25. It looks like widespread delegation of responsibility for SPI.

Misfits between the underlying social networks and a centralized strategy largely explain the failure of the previous centralized SPI initiative. The underiying social networks are uneven and, in the ERP department, developers are unaccustomed to written communication, while in the tailor-made department, the networks are lateral thus less disposed to acting on formal management directive. A centralized strategy is management-driven, communicated in writing, and formal. Either the social networks must change or another strategy must be chosen.

The following ought to concern an SPI manager wanting to embark on an alternative strategy for SPI:

- The remarkably weak ties between the two departments certainly are a hindrance for the central and cross-departmental SPI approach.

- A serious management commitment to SPI will be very difficult to exercise with so little communication on SPI involving the top manager. Maybe the lack of management involvement shows that SPI is not of strategic importance to the company's business strategy. 
- As long as only sparse and formal ties through managers connect the two departments, few improvements will spread easily from one department to the other. Closer ties need to be built between the two departments and at the level of the developers. If this seems impossible or undesirable, one could choose to view the departments as separate social networks and organize independent SPI activities in both, deliberately decreasing knowledge sharing.

- Any SPI initiative in AlphaSoft will benefit from stronger collaboration among the managers and with the CEO involved

- The ERP department could benefit from decentralization, less formalization, and delegation of responsibilities. M-19 could very well be overloaded with responsibilities. If that is the case, he is a bottleneck that stops improvements and hinders knowledge sharing and communication in the company. Management commitment to SPI is based on real involvement and focus, not too much work, and too few resources to deal with it. On the other hand, rather than aiming at central control, AlphaSoft could base this control on mutual adjustment between peers.

- The analyses do not display network structures that hinder ideas and improvements from being communicated among peers (except for the weak ties between departments).

\subsection{The Discussion with the SPI Manager}

A session with the SPI manager, M-19, was organized to present the maps and the researchers' analysis. The main purpose of this session was to push the SPI initiative forward by helping the company to discuss possible ways to support SPI through their social networks. The session followed this agenda:

1. Present and validate the maps of social networks

2. Present the researchers' analysis

3. Discuss the analysis

4. Facilitate the manager's own analysis of the maps

5. Decide which actions should be taken

The maps were presented and explained to the manager as done in sections 4.2 through 4.5. This part of the session was primarily dedicated to the validation of the data underneath the maps. For example, the manager wondered if it was differences in understanding the questionnaire that led to the big difference in written communication between the two departments - or if that really could be the case. He also noticed that a developer with whome he had worked closely was peripheral in the social networkand he wondered why. He found both well-known structures in the maps and surprising structures. It was concluded that the data were sufficiently valid for the present session, but that similar sessions involving more managers and developers should be based on a broader coverage of actors. 
Next, the researchers presented their analysis of the maps as done in section 4.6 . This led to a discussion of both the extent to which the analysis fitted the manager's understanding and the possible ways of supporting SPI through social networks in future. Throughout, the manager listened to the outside view and studied the maps. Gradually, the discussion led the manager to formulate new views on the social networks, and suggestions for how to proceed with SPI.

The discussion did not lead to a specific plan for the next SPI initiative, but it did lead to the recognition that the company needed to work more on analyzing the situation to become successful with the new SPI initiatives. On the one hand, a pure centralized SPI strategy had not worked in the past. On the other hand, a pure peer-driven strategy may not fit the company either. Maybe a mixed strategy could be implemented, but in either case the existing social networks would be insufficient and a change process would have to be considered.

The actions agreed upon were

- Increase the data coverage by making sure that all actors responded to the questionnaire. The mapping of social networks should even be extended to cover the third department, which so far had not been engaged in SPI.

- Immediately organize a similar session with the department managers, M-19 and M-21, and the CEO, M-9. The discussion should be based on the broader coverage.

- Plan, prepare, and realize a seminar for the entire company where the maps were again discussed. The intention should be to arrive at suggestions for how to improve the social networks to form a better foundation for SPI.

\section{DISCUSSION}

In the discussion of the approach to mapping social networks, we first focus on the validity of the research, then on the approach itself, the lessons we have learned about it, and its usefulness in SPI. Second, we focus on the wider research implications and how the approach relates to the existing research on SPI in small and agile companies. Together the discussion covers the six criteria for evaluating action research found in Iversen et al. (2004): roles, documentation, control, usefulness, theory, and transfer. For brevity, only the latter three are emphasized

\subsection{Usefulness and Lessons Learned}

Let us first establish the basis for the action research in terms of the criteria from Iversen et al.

- Roles: Two researchers were active in the research reported here. Both researchers had been involved in the collaboration with the company at the time the idea of social network analysis was introduced. The researchers were responsible for developing the approach and for carrying out most activities. They facilitated the 
activities "use maps in discussions" and "evaluate experience" with the SPI manager as the main contributor.

- Documentation: Data about the action research (not to be confused with the data about social networks) were collected by the researchers through the maps (as in Figures 3 through 6), and the analyses of maps documented in the researchers' notes and diaries from their meetings with the SPI managers.

- Control: The use of social network analysis was initiated by the researchers, but came about during existing collaboration between the researchers and the software company. Authority remained at all times with the company's SPI managers. The action research was governed by an overall contract committing the researchers and the company to collaborate on SPI, but the contract was not detailed and did not stipulate the use of social network analysis.

We have assessed the usefulness of mapping social networks in SPI based on the criterion that the actors acknowledged that learning had occurred, insights had been gained, or even that actions had been taken. In using this pragmatic criterion we concur with several action researchers (e.g., Checkland 1981; Mathiassen 2002).

First, the two researchers and the SPI manager all found that the session in which they used the maps of social networks was valuable. The session advanced the SPI process in several ways.

- The participants came away with a sense of progress similar to that experienced in all problem solving when a better problem definition is reached (explained well by Schön 1983).

- A profound understanding was reached during the session-more profound than what had previously emerged implicitly in discussions among the researchers and the SPI manager.

- Decisions were taken-perhaps not radical decisions, but decisions all the same--that had the potential for making the SPI activity forward. These decisions led to actions being taken to the effect of first involving the other managers, and later involving all developers, in a similar session.

Second, the SPI manager expressed explicitly that the maps were very useful. Not only did the maps show what he already knew, they also contained angles, pointers, and clues that he had never thought about before. He genuinely found the maps interesting as a kind of mirror in which he could now see his own organization in a new light. This was not expressed out of politeness as he had on several previous occasions expressed dissatisfaction with the researchers' ideas and did not have any academic or theoretical interest.

Third, the two researchers found the approach and the maps useful. The maps aided in understanding why several previous attempts at improving software processes had failed. The maps also indicated how the researchers could become more successful as facilitators of process improvement. 
In addition to this general assessment of usefulness, there are a number of specific lessons learned about the approach.

- Maintaining that the maps are a means for discussion and debate among the actors involved is crucial; they do not represent real-world social networks. Hence, the data's objectivity or accuracy is not of paramount importance; it is sufficient that the data reflect actors' perceptions of their communication about improvement.

- The data collection for the maps can be very fast and efficient. In our data collection, we did not cover the entire company, but full coverage could be achieved efficiently. On the other hand, if the data collection becomes too relaxed, the actors involved may not want to discuss the maps, or they will not take action based on the maps. That will seriously jeopardize the mapping approach.

- Collecting data about actors' perceptions of communication with other actors, and even based on the recollection of activity for the last six months, does not signal validity of data. In the validation we experienced, it did not become an issue. On the other hand, it is possible to reduce the reliance on recollection by tracking actors' perceptions of communication over a period.

- The tool we used, NetDraw, has been very helpful in the process. After some initial problems with data formats, it has consistently supported not only the drawing of maps based on the data, but also a number of the most common algorithmic analyses that can be performed on social networks. The tool works well with small amounts of data when there is a need for visualization. It is not likely to be as valuable with large amounts of data, as large social networks are not easy to visualize.

\subsection{Implications for SPI in Small Companies}

Our mapping approach relates to the existing theories of SPI in small companies in the following ways. First, the mapping of social networks, as in the approach we used at AlphaSoft, seems particularly relevant for understanding SPI activity in small companies. Small software companies are less likely to favor a formal, centralized SPI approach as discussed in the introduction. AlphaSoft conforms to earlier reports (CaterSteel 2001; Kelly and Culleton 1999; Villalon et al. 2002; Ward et al. 2001) in that

1. They did not want to invest as much in SPI as the companies following the CMM.

2. The formal and centralized SPI approach did not fit their small company culture.

3. They to some extent lacked SPI knowledge.

4. Actions were less planned.

5. They were very sensitive to their changing environment (i.e., market segment changes).

In this setting, mapping fits well as a low-budget approach to assess strengths and weaknesses in the social networks. This is an important part of the infrastructure for informal SPI because such companies lack the economical inclination to invest in a 
formal, rational, centralized infrastructure. It enables companies to discuss and exploit the possibilities that already exist and to focus on necessary improvements.

Second, the ability to change with a changing environment is an agile property of a software company. The ability to change requires, among other things, well-functioning communication (Ward et al. 2001). It is thus desirable to analyze the social network of communication to ensure this important principle is the basis for constantly changing processes and, hopefully, improvements.

Third, agile software development requires particular activity to implement SPI (Börjesson and Mathiassen 2004), but most small software companies focus on agile properties directly related to development activities (e.g., changing requirements, technology, and innovation). As we see it, changing requirements, technologies, and markets may well demand more improvement. In the small software company, this activity again ought to be supported by the same kind of social networks. Further, Börjesson and Mathiassen state that an agile software organization needs to balance and coordinate development, improvement, and innovation. However, all of the studies of SPI in small software companies mentioned in the introduction found that that is exactly what they are not doing - and with good reasons. Like AlphaSoft, they prioritize development over improvement. Therefore, while studying the social networks of communication about SPI in AlphaSoft, we began to wonder what the networks of development looked like and if we, instead of improving and building SPI social networks, could piggyback on the working, and probably more stable, social networks supporting development. We could map the social networks of communication on development and perhaps investigate if, and how, the small company could do SPI while primarily attending to development.

Our mapping approach could be transferred to other, similar situations. Based on our, so far, limited experience with the mapping approach, we suggest that it will work for small companies, but not large ones. To facilitate discussions that bring the process forward, the maps of social networks must show the networks in a highly visual way that can be grasped by the actors involved without them being experts on social network analysis.

Consideration of whether practitioners can use the approach independently (i.e., without the researchers' presence) is always relevant for approaches stemming from action research. Actors who possess a theoretical and practical competence in social network analysis may develop maps, while those possessing more general process facilitation skills lead the activities in which maps are used to spark discussion.

Very little in the mapping approach is specific to AlphaSoft. The data collection methods and development, analysis, and use of maps in discussions are all transferable to other small, agile software organizations. For these parts, we claim some generality. What cannot be transferred to other organizations are the specific maps, the analyses of AlphaSoft through maps, and the specific outcomes of the discussions. For that, we claim no generality.

\section{CONCLUSION}

We have tried here to answer the research question: To what extent and in which ways is the mapping of social networks useful in SPI in a small company? In this paper, 
we have addressed this by outlining an approach for mapping social networks that may be used in SPI initiatives. Through action research, we have shown how we used the approach in AlphaSoft, and we have discussed its usefulness, relation to theory in the field, and circumstances under which it may be transferred to other situations.

There are several limitations in our action research and use of social network analysis. Further research needs to be done to

1. Improve the mapping approach, particularly how to efficiently collect valid data and decide which maps to develop and bring to the discussion

2. Test the approach further; it is particularly relevant to test the approach in other small software companies showing a wide range of characteristics

3. Develop implications for SPI that can be drawn from the maps of social networks

\section{REFERENCES}

Aaen, I., Arendt, J., Mathiassen, L., and Ngwenyama, O. "A Conceptual MAP of Software Process Improvement," Scandinavian Journal of Information Systems (13), 2001, pp. 81-101.

Borgatti. S. P., and Everett, M. G. "Notions of Position in Social Network Analysis," Sociological Methodology (22) 1992, pp. 1-35.

Brodman, J. G., and Johnson, D. L. "What Small Businesses and Small Organizations say about the CMM," in Proceedings of the $16^{\text {in }}$ International Conference on Software Engineering, Sorrento, Italy, 1994, pp. 331-340.

Börjesson, A., and Mathiassen, L. "Improving Software Organizations: The Agility Challenge," unpublished manuscript submitted to a journal, 2004.

Cater-Steel, A. P. "Process Improvement in Four Small Software Companies," in Proceedings of the 2001 Australian Software Engineering Conference, Los Alamitos, CA: IEEE Computer Society Press, 2001, pp. 262-272.

Checkland, P. Systems Thinking, Systems Practice, Chichester, England: Wiley, 1981.

Hansen, B., Rose. J., and Tjørnehøj, G. "Prescription, Description, Reflection: The Shape of the Software Process Improvement Field," paper presented at the UK Association of Information Systems Conference, Glasgow Caledonian University, Glasgow, Scotland, 2004.

Haythornthwaite, C. "Social Network Analysis: An Approach and Technique for the Study of Information Exchange," Library and Information Science Research (18), 1996, pp. 323-342.

Hult, M., and Lennung, S.-A. "Towards a Definition of Action Research: A Note and Bibliography," Journal of Management Studies, May 1980, pp. 241-250.

Iversen, J. H., Mathiassen, L., and Nielsen, P. A. "Managing Risk in Software Process Improvement: An Action Research Approach," MIS Quarterly (28:3), 2004, pp. 395-433.

Iversen, J., Nielsen, P.A., and Nørbjerg, J. "Situated Assessment of Problems in Software Development," The DATABASE for Advances in Information Systems (30:2), 1999, pp. 66-81.

Kelly, D. P., and Culleton, B. "Process Improvement for Small Organizations," Computer (32:10), 1999, pp. 41-47.

Kotter, J. P. "Power, Dependence, and Effective Management," in Organizational Influence Processes, R. W. Allen and L. W. Porter (Eds.), Glenview, IL: Scott, Foresman and Company, 1983, pp. 128-143.

Martínez, A., Dimitriadis, Y., Rubia, B., Gómez, E., and de la Fuenta, P. "Combining Qualitative Evaluation and Social Network Analysis for the Study of Classroom Social Interactions," Computers \& Education (41), 2003, pp. 353-368. 
Mathiassen, L. "Collaborative Practice Research," Information Technology \& People (15:4), 2002, pp. $321-345$.

McKay, J., and Marshall, P. "The Dual Imperatives of Action Research," Information Technology \& People (14:1), 2001, pp. 46-59.

Ngwenyama, O., and Nielsen, P. A. "Competing Values in Software Process Improvement: An Assumption Analysis of CMM from an Organizational Culture Perspective," IEEE Transactions on Engineering Management (50:1), 2003, pp. 100-112.

Nielsen, P. A., Iversen, J. H., Johansen, J., and Nielsen, L. B. "The Adolescent Effort," in Improving Software Organizations: From Principles to Practice, L. Mathiassen, J. PriesHeje, and O. Ngwenyama (Eds.), Reading, MA: Addison-Wesley, 2002.

Nielsen, P.A., and Ngwenyama, O. "Organizational Influence Processes in Software Process Improvement," European Conference on Information Systems, Gdansk, 2002.

Richardson, I. "SPI Models: What Characteristics Are Required for Small Software Development Companies?," Software Quality Journal (10:2), 2002, pp. 101-114.

Schön, D. The Reflective Practitioner: How Professionals Think in Action, New York: Basic Books, 1983.

Scott, J. Social Network Analysis: A Handbook ( $2^{\text {nd }}$ ed $)$, London: Sage Publications, 2000.

Temdee, P., and Korba, L. "Of Networks, Interactions and Agents: An Approach for Social Network Analysis," in Proceedings of the Sixth International Conference on Computer Supported Cooperative Work in Design, Ottawa: NRC Research Press, 2001, pp. 324-329.

Tichy, N. M., Tushman, M. L., and Fombrun, C. "Social Network Analysis for Organizations," The Acadeny of Management Review (4:4), 1979, pp. 507-519.

Villalon, J., Agustin, G. C., Gilabert, T. S. F., Seco, A. D., Sanchez, L. G., and Cota, M. P. "Experiences in the Application of Software Process Improvement in SMES," Software Quality Journal (10:3), 2002, pp. 261-273.

Ward, R. P., Fayad, M. E., and Laitinen, M. "Software Process Improvement in the Small," Communications of the ACM (44:4), 2001, pp. 105-107.

Wasserman, S., and Faust, K. Social Network Analysis: Methods and Applications, Cambridge, England: Cambridge University Press, 1994.

Zack, M. H. "Researching Organizational Systems using Social Network Analysis," in Proceedings of the $33^{\text {rd }}$ Hawail International Conference on Systems Science, Los Alamitos, CA: IEEE Computer Society Press, 2000.

\section{ABOUT THE AUTHORS}

Peter Axel Nielsen is an associate professor in Information Systems at the Department of Computer Science at Aalborg University. Over the past years he has been engaged in understanding information systems development practice and the use of methodologies. His research interests include analysis and design techniques, object-orientation, and software process improvement. He is coauthor of a book on object-oriented analysis and design and a book on software process improvement. Peter can be reached at pan@cs.aau.dk.

Gitte Tjornehoj is an assistant professor and Ph.D. student at the Department of Computer Science, Aalborg University, Denmark. She is a member of the SPV research project in Denmark. Her research is rooted in 10 years experience working in the IT industry. Her main research interests are management of IT and IS development focused on organisational change. Gitte can be reached at gtj@cs.aau.dk. 